\title{
Subjective Memory Immediately Following Electroconvulsive Therapy
}

\begin{abstract}
Brus Ole, Nordanskog Pia, Båve Ullvi, Cao Yang, Hammar Åsa, Landén Mikael, Lundberg
\end{abstract} Johan and Nordenskjöld Axel

\section{Journal Article}

\section{Tweet}

N.B.: When citing this work, cite the original article.

Original Publication:

Brus Ole, Nordanskog Pia, Båve Ullvi, Cao Yang, Hammar Åsa, Landén Mikael, Lundberg Johan and Nordenskjöld Axel, Subjective Memory Immediately Following Electroconvulsive Therapy, Journal of ECT, 2016.

\section{http://dx.doi.org/10.1097/yct.0000000000000377}

Copyright: Lippincott, Williams \& Wilkins

http://www.lww.com/

Postprint available at: Linköping University Electronic Press

http://urn.kb.se/resolve?urn=urn:nbn:se:liu:diva-134894

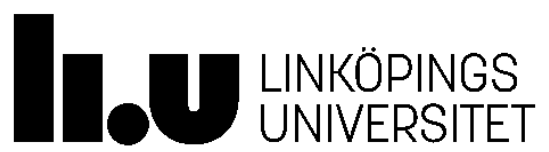




\title{
Subjective Memory Immediately Following Electroconvulsive Therapy
}

\author{
Ole Brus, MSc, * Pia Nordanskog, MD, PhD, †ł Ullvi Båve, MD, PhD, \& Yang Cao, PhD, *// \\ Asa Hammar, MD, PhD, $9 \#$ \# Mikael Landén, MD, PhD, **† \\ Johan Lundberg, MD, PhD, $+千$ and Axel Nordenskjöld, MD, PhD\$ई
}

\begin{abstract}
Objectives: The aims of the present study were to describe the short-term rate of subjective memory worsening (SMW) and identify factors of importance for SMW in a large clinical sample treated for depression with electroconvulsive therapy (ECT).

Methods: This register-based study included 1212 patients from the Swedish National Quality Register for ECT. Subjective memory worsening was defined as a 2-point worsening on the memory item of the Comprehensive Psychopathological Rating Scale from before to within 1 week after treatment. Associations between patient characteristics and treatment factors were examined using logistic regression.

Results: Subjective memory worsening was experienced in $26 \%$. It was more common in women than in men $(31 \%$ vs $18 \% ; P<0.001)$ and more common in patients aged 18 to 39 years than in patients 65 years or older ( $32 \%$ vs $22 \% ; P=0.008$ ). Patients with less subjective memory disturbances before ECT had a greater risk of SMW. Patients in remission after ECT had a lower risk of SMW. A brief pulse width stimulus gave higher risk of SMW compared with ultrabrief pulse (odds ratio, 1.61; $95 \%$ confidence interval, 1.05-2.47).

Conclusions: Subjective memory worsening is reported by a minority of patients. However, young women are at risk of experiencing SMW. Ultrabrief pulse width stimulus could be considered for patients treated with unilateral electrode placement who experience SMW. Each patient should be monitored with regard to symptoms and adverse effects, and treatment should be adjusted on an individual basis to maximize the clinical effect and with efforts to minimize the cognitive adverse effects.
\end{abstract}

Key Words: amnesia, electroconvulsive therapy, memory

(J ECT 2016;00: 00-00)

From the *Clinical Epidemiology and Biostatistics, School of Medical Sciences, Örebro University, Örebro; $\dagger$ Center for Social and Affective Neuroscience, Department of Clinical and Experimental Medicine, Faculty of Health Sciences, Linköping University, Linköping; †Department of Psychiatry, Region Östergötland, Linköping; §Department of Clinical Neuroscience, and \|Unit of Biostatistics, Institute of Environmental Medicine, Karolinska Institutet, Stockholm, Sweden; 9 Department of Biological and Medical Psychology, University of Bergen, Bergen; \#Division of Psychiatry, Haukeland University Hospital, Bergen, Norway; **Department of Medical Epidemiology and Biostatistics, Karolinska Institutet, Stockholm; ††Institute of Neuroscience and Physiology, The Sahlgrenska Academy at Gothenburg University, Gothenburg; $\$$ \$Centre for Psychiatry Research, Department of Clinical Neuroscience, Karolinska Institutet, Stockholm; and $\S \S$ School of Medical Sciences, Örebro University, Örebro, Sweden.

Received for publication July 11, 2016; accepted October 23, 2016

Reprints: Ole Brus, MSc, Clinical Epidemiology and Biostatistics, X-huset, Örebro University Hospital, 70185 Örebro, Sweden (e-mail: ole.brus@regionorebrolan.se).

This research was supported by Swedish Research Council (523-2013-2982) and the Swedish Foundation for Strategic Research.

The authors have no conflicts of interest or financial disclosures to report.

Copyright $(\subset) 2016$ Wolters Kluwer Health, Inc. All rights reserved. This is an open-access article distributed under the terms of the Creative Commons Attribution-Non Commercial-No Derivatives License 4.0 (CCBY-NC-ND), where it is permissible to download and share the work provided it is properly cited. The work cannot be changed in any way or used commercially without permission from the journal.

DOI: $10.1097 /$ YCT.0000000000000377
E lectroconvulsive therapy (ECT) is an effective treatment for seE vere depression ${ }^{1}$ but entails cognitive adverse effects, particularly the effects on memory. ${ }^{2-4}$ Electroconvulsive therapy may cause a temporary deficit in the cognitive processes of information encoding, consolidation, and retrieval. ${ }^{5}$ Transient memory disturbances are regarded as an inevitable adverse effect of therapeutic convulsions. ${ }^{6}$ Various strategies have been tried to decrease the cognitive adverse effects while retaining the antidepressant effect, including the use of unilateral instead of bilateral electrode placement, changes in waveform, and reducing the electrical stimulus intensity. ${ }^{7}$

In a systematic review and meta-analysis, Semkovska and McLoughlin 5 found little evidence of cognitive deficits lasting longer than a few days after ECT. The review was based on objective measures such as performances on standardized tests that but lacked measures of retrograde autobiographical memory and patients' subjective reports.

Even though many patients report subjective memory improvement after ECT, 8 some experience subjective memory worsening (SMW). Subjective memory worsening after ECT decreases the benefit of the treatment. ${ }^{9,10}$

Subjective memory complaints are not always well correlated with deterioration of objective measures of memory. Nevertheless, studies have associated subjective memory complaints after ECT with performance in an autobiographical interview conducted several months after ECT. ${ }^{12,13}$

Mood state has been related to subjective memory complaints after ECT. ${ }^{8,11,14}$ Depression is associated with subjective memory disturbances, ${ }^{15}$ and long-lasting cognitive deficits can persist and cause functional impairment in remitted patients who were never treated with ECT. ${ }^{16}$ In general, impairment in executive functioning and attention has been found to be more stable cognitive deficits persisting despite improved clinical status, whereas the cognitive functions of memory, verbal fluency measures, and psychomotor speed have been suggested to be more related to clinical state. ${ }^{17}$ The extent to which subjective memory complaints in ECT-treated depression patients relate with the treatment, the disease, or some other factor remains uncertain. How patients experience the duration of the memory deficits after modern ECT is also unclear. ${ }^{18-20}$

There have been attempts to relate subjective memory disturbances after ECT to treatment variables such as electrode placement, number of treatments, waveform, and charge. ${ }^{8}$ There is some evidence that sine wave stimulus may cause more disturbances than brief pulse stimulus and that bilateral electrode placement may cause more disturbances than unilateral electrode placement, but the findings are inconsistent. ${ }^{8}$ This contrasts the evidence for objective cognitive measures where higher electrical charge causes more cognitive adverse effects and also stronger antidepressant effect than lower electrical charge. Moreover, some studies have indicated that bilateral electrode placement has higher efficacy as well more cognitive adverse effects than unilateral electrode placement. $^{21}$ 
There is a paucity of studies relating clinical factors to patients' experience of memory disturbances after ECT. ${ }^{8}$ Identifying patients who are more likely to experience SMW is important for clinical decision making, where ECT should be tailored to the individual patients to maximize clinical effect and minimize adverse effects. If the indication for ECT is weak, and the risk of SMW is high, alternative treatments could be considered. On the other hand, if the risk of SMW is low, this might influence a patient to choose ECT over pharmacotherapy.

The aim of this study was to describe the short-term rate of SMW and identify factors of importance for SMW in a large clinical sample treated for depression with ECT.

\section{MATERIALS AND METHODS}

\section{Study Design}

This register-based study used data from the Swedish National Quality Register for ECT, which holds nationwide data for outcomes of ECT performed in Sweden since 2011. The register had a coverage of $85 \%$ for all ECT series performed in Sweden in 2013 and a coverage of $89 \%$ in $2014 .^{22}$

The quality register was linked to the mandatory Swedish Patient Register to identify patients with personality disorders. The patient register holds information on inpatients who received a diagnosis since 1964 and outpatients who received a diagnosis since $2001 .{ }^{23}$ We identified all personality disorder diagnoses (Swedish version of the International Classification of Diseases version 10 $[I C D-10-S E]$ codes $\mathrm{F} 60, \mathrm{~F} 61$, and $\mathrm{F} 62)^{24}$ recorded before ECT.

\section{Electroconvulsive Therapy}

Electroconvulsive therapy was administered by using bidirectional constant current, brief-pulse devices. Mecta devices (Mecta Corp, Lake Oswego, Ore) and Thymatron devices (Somatics, Inc, Lake Bluff, Ill) were used for 916 and 296 patients, respectively. Electroencephalography was used to monitor the patients during the treatment. During the procedure, the patients were sedated using propofol or thiopenthal. Succinylcholine $(1 \mathrm{mg} / \mathrm{kg})$ was used as muscle relaxant, and glycopyrrolate $(0.2 \mathrm{mg})$ or atropine was used as an anticholinergic agent when necessary. The mean charges were 351 (SD, 143) $\mathrm{mC}$ for the unilateral electrode placement group, 417 (SD, 192) $\mathrm{mC}$ for the bitemporal electrode placement group and 260 (SD, 76)mC for the bifrontal electrode placement group.

\section{Outcome}

Subjective memory disturbance was rated using the 7-point variant of item 17 "failing memory" of the Comprehensive Psychopathological Rating Scale (CPRS). ${ }^{25}$ The CPRS compromises 65 items and was developed during the 1970s for evaluation of psychiatric treatment effects. It has high reliability ${ }^{26}$ and can be used in full or as an "item pool," for example, the MontgomeryÅsberg Depression Rating Scale (MADRS), which consists of 10 items from the CPRS. Item 17 of the CPRS represents subjective disturbances of recall compared with previous ability and is distinguished from concentration difficulties. The scale steps are as follows: $0=$ memory as usual, $2=$ occasional increased lapses of memory, $4=$ reports of socially inconvenient or disturbing loss of memory, $6=$ complaints of complete inability to remember. ${ }^{25} \mathrm{~A}$ physician, an ECT nurse, or other professional who was involved in administering the ECT treatment recorded the score based on the patients' subjective report. Subjective memory worsening was operationally defined as a worsening of at least 2 points (eg, from 2 to 4 ) on the item score from within 1 week before to within 1 week after treatment.

\section{Factors of Interest}

The severity of depressive symptoms was rated using the self-assessment version of MADRS (MADRS-S). The scale consists of 9 items, and each item is scored from 0 (no symptoms) to 6 (severe symptoms). The maximum possible score is 54 points. ${ }^{27}$ The MADRS-S scores before ECT were divided into 3 categories ( $<20$ points, $20-35$ points, and $\geq 36$ points) to indicate the degrees of severity. The MADRS-S scores after ECT were divided into 2 categories: 0 to 10 (in remission) and 11 or greater (not in remission) for remission is a goal of the treatment. ${ }^{28}$

Diagnoses were categorized based on the ICD-10-SE diagnosis into unipolar depression and bipolar depression. Diagnoses were also categorized as with or without psychotic features. Information about the following drug treatments, at the end of ECT, was obtained from the quality register: antidepressants, lithium, lamotrigine, valproate, benzodiazepines, other antiepileptic drugs, and antipsychotic medication. The diagnoses used were F32.1, F32.2, F32.3, F33.1, F33.2, F33.3, F31.3, F31.4, and F31.5.

\section{Inclusion and Exclusion Criteria}

Patients treated with ECT for depression according to $I C D-10-S E$ and registered in the Swedish National Quality Register for ECT were included. When a patient had multiple series that fulfilled the inclusion requirement, only the earliest treatment series was used. Patients were excluded if any of the following information was missing in the register: subjective memory disturbances before or after treatment, sex, age, number of treatments in the treatment series, MADRS-S score, diagnosis, electrode placement, or any of pulse width, frequency, duration, or current. Six patients who rated their subjective memory disturbances in the 2 worst categories before treatment were excluded because it was not possible for their memory to worsen by 2 points (Fig. 1).

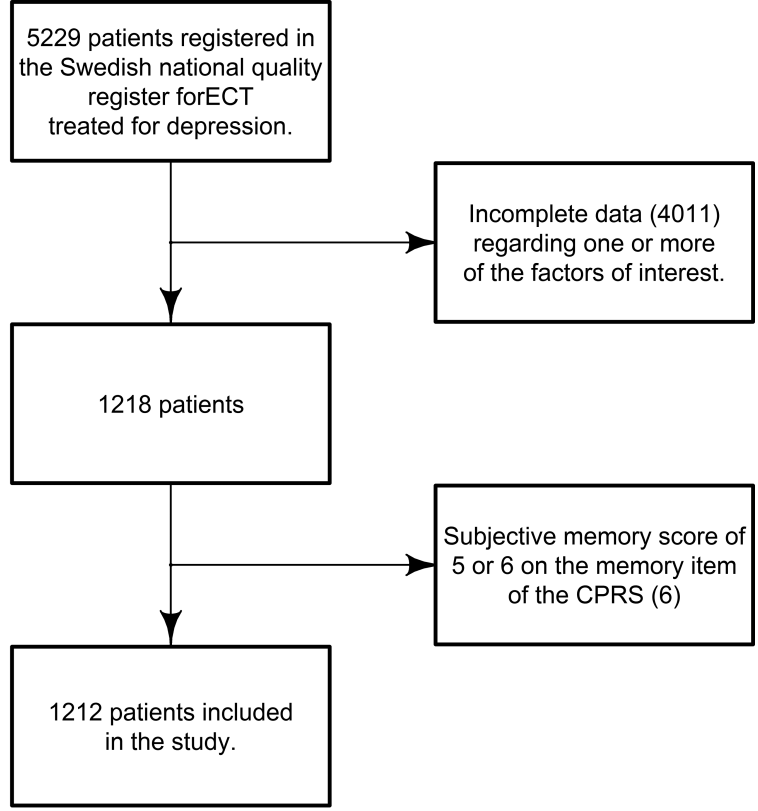

$\mathrm{ECT}=$ Electroconvulsive therapy

CPRS $=$ Comprahensive psychopathological rating scale

FIGURE 1. Flowchart of included and excluded patients. 


\section{Study Population}

Among the 1212 patients included in the study, 60\% were women. The mean age was 53 years (range, 18-95 years), and the mean MADRS-S score was 33 points before and 15 points after ECT. The diagnosis was unipolar depressive episode for $80 \%$ and bipolar depression for $20 \%$. Depression with psychotic features was present in $14 \%$ of the patients. The characteristics of the population are presented in Table 1 . The treatments were performed at 41 Swedish hospitals between March 2011 and December 2014.

The proportion of women in the study sample was approximately the same as in the rest of the registry $(60 \%$ vs $63 \%$, $P=0.056$ ). Although the mean age of the included patients in the study (53.4 years) was statistically significantly different from the rest of the patients in the registry (52.1 years, $P=0.024$ ), we do not believe the 1.3 -year difference in age to be of clinical relevance.

\section{Statistical Methods}

The associations of SMW with sex, age, number of treatments, electrode placement, and personality disorders were evaluated using logistic regression analysis through least square optimization in both unadjusted and adjusted models. The following potential confounding variables were included in the adjusted models: sex, age, diagnosis, psychotic features, personality disorders, MADRS-S score categories before and after ECT, subjective memory estimation before ECT, number of ECT sessions, electrode placement, and medications. Factors that were statistically significant in the adjusted or unadjusted models were then pairwise post hoc tested for interaction using logistic regression. Odds ratios (ORs) and corresponding 95\% confidence intervals (CIs) were calculated for the risk of SMW.

The association between electrical dosage and SMW was analyzed for patients treated with unilateral electrode placement. The same variables were adjusted for as in the model for the total population (except for electrode placement and medication) and further adjusted for pulse width, frequency, duration, and current.

Differences in distribution of sex and age categories between patients with missing data and patients included in the study were tested using $\chi^{2}$ tests and $t$ tests. Differences in proportion of SMW between patients with and without personality disorder stratified by age group and sex were analyzed using $\chi^{2}$ tests. The difference in subjective memory estimation before and after treatment was tested using Wilcoxon signed rank test.

Continuous variables were categorized to be able to identify potential nonlinear relations to SMW. In addition, tests were performed of linear and quadratic trends for continuous variables.

Data management and analyses were performed in the statistical packages SPSS 22 (IBM Corp, Armonk, NY) and SAS 9.4 (SAS Institute, Cary, NC). The figures were created in R 3.2.5 (R Foundation for Statistical Computing, Vienna, Austria).

\section{Ethics}

The Regional Ethical Vetting Board in Uppsala, Sweden, approved the study. The patients were informed about the quality register and had the option to decline participation.

\section{RESULTS}

\section{Subjective Memory Before and After Treatment}

Before treatment, 1016 patients (84\%) had no subjective memory disturbances or occasional increased lapses of memory (subjective memory score 0 to 2); after ECT, the corresponding number was 934 (77.1\%) (Fig. 2). Sixty-eight percent of the patients had no memory disturbances or occasional increased lapses of memory both before and after treatment. Fifteen percent of patients deteriorated by 1 point, and $10 \%$ improved by 1 point after treatment. Improvement of 2 or more points (subjective memory

TABLE 1. Characteristics of the Study Population

\begin{tabular}{|c|c|c|c|c|}
\hline & & No SMW & SMW & Total \\
\hline & & n (\%) & n (\%) & n (\%) \\
\hline \multirow[t]{2}{*}{ Sex } & Female & $506(56.3)$ & $226(72.2)$ & $732(60.4)$ \\
\hline & Male & $393(43.7)$ & $87(27.8)$ & $480(39.6)$ \\
\hline \multirow[t]{3}{*}{ Age, y } & $18-39$ & $191(21.2)$ & $89(28.4)$ & $280(23.1)$ \\
\hline & $40-64$ & $436(48.5)$ & $146(46.6)$ & $582(48.0)$ \\
\hline & $\geq 65$ & $272(30.3)$ & $78(24.9)$ & $350(28.9)$ \\
\hline \multirow[t]{2}{*}{ Depression diagnosis } & Unipolar depression & $724(80.5)$ & $243(77.6)$ & $967(79.8)$ \\
\hline & Bipolar depression & $175(19.5)$ & $70(22.4)$ & $245(20.2)$ \\
\hline \multirow[t]{2}{*}{ Psychotic features } & Yes & $131(14.6)$ & $41(13.1)$ & $172(14.2)$ \\
\hline & No & $768(85.4)$ & $272(86.9)$ & $1040(85.8)$ \\
\hline \multirow[t]{2}{*}{ Personality disorder } & Yes & $118(13.1)$ & $51(16.3)$ & $169(13.9)$ \\
\hline & No & $781(86.9)$ & $262(83.7)$ & $1043(86.1)$ \\
\hline \multirow{3}{*}{ MADRS-S score before ECT } & $0-19$ & $69(7.7)$ & $22(7.0)$ & $91(7.5)$ \\
\hline & $20-35$ & $474(52.7)$ & $158(50.5)$ & $632(52.1)$ \\
\hline & $\geq 36$ & $356(39.6)$ & $133(42.5)$ & $489(40.3)$ \\
\hline \multirow[t]{2}{*}{ MADRS-S score after ECT } & $0-10$ & $375(41.7)$ & $108(34.5)$ & 483 (39.9) \\
\hline & $\geq 11$ & $524(58.3)$ & $205(65.5)$ & $729(60.1)$ \\
\hline \multirow[t]{3}{*}{ No. of ECT sessions } & $1-5$ & $109(12.1)$ & 49 (15.7) & $158(13.0)$ \\
\hline & $6-9$ & $539(60.0)$ & $168(53.7)$ & $707(58.3)$ \\
\hline & $\geq 10$ & $251(27.9)$ & $96(30.7)$ & 347 (28.6) \\
\hline \multirow[t]{3}{*}{ Electrode placement } & Unilateral & $823(91.5)$ & $287(91.7)$ & $1110(91.6)$ \\
\hline & Bitemporal & $49(5.5)$ & $16(5.1)$ & $65(5.4)$ \\
\hline & Bifrontal & $27(3.0)$ & $10(3.2)$ & $37(3.1)$ \\
\hline
\end{tabular}




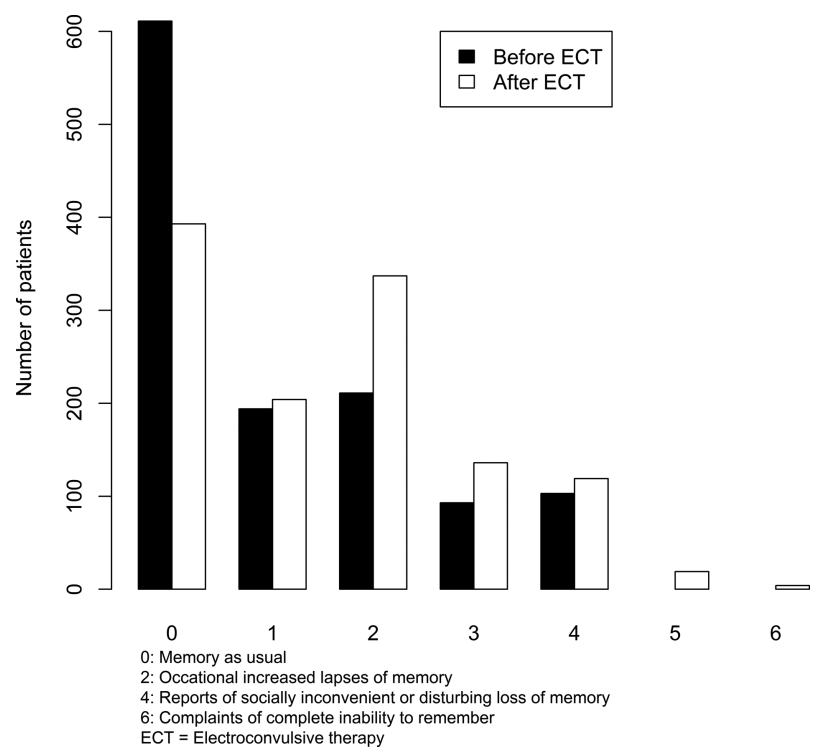

FIGURE 2. Subjective memory rating before and within 1 week after ECT.

improvement) occurred for 120 patients (10\%). In total, 313 patients $(26 \%)$ had SMW. Median subjective memory estimation before treatment was 0 (first and third quartiles: 0 and 2), and after treatment, the median was 2 (first and third quartiles: 0 and 2), $P<0.001$.

\section{Age and Sex}

Lower age and female sex were statistically significantly associated with SMW. The proportion of patients with SMW was lower in men than in women $(18 \%$ vs $31 \% ; P<0.001)$. Subjective memory worsening was more common among young than among old patients $(32 \%$ in patients aged $18-39$ years, $22 \%$ for patients $\geq 65$ years; $P=0.008)$. This trend was significant in linear logistic regression analysis, OR per year 0.99 ; $95 \% \mathrm{CI}, 0.98-1.00, P=0.003$.

For women younger than 40 years, aged 40 to 64 years, and 65 years or older, $38 \%, 31 \%$, and $26 \%$ had SMW, respectively. The corresponding numbers for men were $23 \%, 17 \%$, and $16 \%$.

\section{Baseline Subjective Memory Estimation}

Subjective memory worsening was significantly more common among patients without subjective memory disturbances before ECT $(39 \%)$ than among those with subjective memory disturbances who scored 1 or $2(17 \%)$ and 3 or $4(1.5 \%)$ on the memory item of the CPRS (Table 2). This trend was significant in a linear logistic regression model OR (0.29-0.42), $P<0.001$.

\section{Diagnosis, Severity and Comorbidity}

Subjective memory worsening was reported by $26 \%$ of the depressed patients without psychotic features and by $24 \%$ of depressed patients with psychotic features $(P=0.827)$. There were no statistically significant differences in the frequency of SMW between patients with bipolar and unipolar depression (Table 2).

Among patients with self-assessed MADRS-S score less than 20 before treatment, 24\% experienced SMW. For those with 20 to 35 MADRS-S points, $25 \%$ had SMW, and for those with 36 points or greater, the corresponding number was $27 \%$. These group differences were not statistically significant (Table 2 ).

Subjective memory worsening was reported in $22 \%$ of the patients in remission (MADRS-S score $\leq 10$ ) after ECT and in $28 \%$ of the patients who did not attain remission $(P=0.013)$ (Table 2$)$.
In total, 169 patients $(14 \%)$ received a diagnosis of personality disorders. The most common personality disorders were borderline personality disorder $(\mathrm{F} 60.3, \mathrm{n}=89)$ and unspecified personality disorder $(\mathrm{F} 60.9, \mathrm{n}=56)$.

There was no increased risk of SMW for patients with personality disorders compared with those without either in the unadjusted analysis (OR, 1.29; 95\% CI, 0.90-1.84) or the adjusted analysis (OR, $0.88 ; 95 \% \mathrm{CI}, 0.57-1.34$ ).

Most patients with personality disorders were women younger than 65 years $(69 \%)$. Among the 56 women younger than 40 years with personality disorders, 22 had SMW; this compares with 41 of 110 women younger than 40 years without personality disorders ( $39 \%$ vs $37 \%, P=0.801$ ). For women aged 40 to 64 years, the corresponding numbers were 19 of 61 and 85 of 275 , respectively $(31 \%$ vs $31 \% P=0.971)$.

\section{ECT Treatment}

Subjective memory worsening occurred in $26 \%$ of patients treated with unilateral electrode placement, in $25 \%$ of the patients treated with bitemporal electrode placement, and in $27 \%$ of patients treated with bifrontal electrode placement. There was no statistically significant association between electrode placement and SMW (Table 2).

Subjective memory worsening occurred in $31 \%$ of the patients who received between 1 and 5 ECT session, 24\% of the patients who received between 6 and 9 ECT sessions, and $28 \%$ of the patients who received 10 or more ECT sessions. The risk of SMW was borderline lower for patients who received between 6 and 9 ECT sessions compared with patients who received between 1 and 5 sessions (OR, 0.69 [95\% CI, 0.47-1.01] and OR, 0.67 [95\% CI, 0.43-1.02] in unadjusted and adjusted models, respectively). There was no significant linear or quadratic trend in logistic regression models.

The subgroup analysis was conducted for 1110 patients treated with unilateral electrode placement. In the unadjusted model, the risk of SMW was not statistically significantly different between patients treated with brief pulse width and those treated with ultrabrief pulse width (OR, 1.21; 95\% CI, 0.86-1.70). However, the adjusted model indicated a statistically significant increased risk of SMW (OR, 1.61; 95\% CI, 1.05-2.47) in patients treated with brief pulse width. This trend was significant also in a linear logistic regression model OR per millisecond (1.7623.22), $P=0.005$. There were no statistically significant differences in the risks of SMW among patients treated with different frequencies durations or electric charge. In a model estimating a linear effect of electrical current dose, there was a trend of increased SMW for higher current (OR per mA increase: 1.00 $[1.00-1.01])$. This pattern was not seen in the model with categorized data (Table 3).

\section{Pharmaceuticals}

Subjective memory worsening was more common among patients with lithium treatment then without $(31 \%$ vs $25 \%$, $P=0.091)$. This difference was statistically significant in the adjusted model (OR, 1.58; 95\% CI, 1.04-2.41), but not in the unadjusted model (OR, 1.34; 95\% CI, 0.95-1.88). There were no statistically significant differences in the risk of SMW between patients receiving antidepressants, lamotrigine, valproate, benzodiazepines, other antiepileptics, or antipsychotics and those not (Table 2).

\section{Interaction Effects}

In the post hoc analysis for pairwise interaction, no statistically significant interaction was found. 


\section{DISCUSSION}

We studied clinical risk factors for SMW after ECT in 1212 patients. The main findings were that female sex and younger age were risk factors for SMW.

The finding that SMW was more common among women is in line with another study relating female sex to poorer performance on the Mini-Mental State Examination and objective cognitive test results after ECT, such as Rey's complex figure test reproduction measuring visual and spatial memory and the
Autobiographical Memory Inventory-Short Form. ${ }^{2}$ Moreover, female sex has been associated with poorer performance on the spatial recognition memory task from the Cambridge Neuropsychological Test Automated Battery. ${ }^{29}$

Young patients were more likely to experience SMW than older patients. This finding is in line with another study of subjective memory disturbances after ECT by Berman et al ${ }^{12}$ By contrast, older age has been associated with a greater increase in cognitive disturbances after ECT. ${ }^{2}$ One possible reason for this discrepancy between subjective and objective memory

TABLE 2. Associations Between SMW and Factors of Interest

\begin{tabular}{|c|c|c|c|c|c|}
\hline & & \multirow{2}{*}{$\frac{\text { No SMW }}{n(\%)}$} & \multirow{2}{*}{$\frac{\text { SMW }}{\text { n (\%) }}$} & \multicolumn{2}{|c|}{ Adjusted Model* } \\
\hline & & & & OR (95\% CI) & $\boldsymbol{P}$ \\
\hline Sex & Male & 393 (81.9) & $87(18.1)$ & $0.36(0.26-0.49)$ & $<0.001$ \\
\hline \multirow{2}{*}{ Age, y } & $18-39$ & $191(68.2)$ & $89(31.8)$ & $1.79(1.17-2.75)$ & 0.008 \\
\hline & $40-64$ & $436(74.9)$ & $146(25.1)$ & $1.12(0.78-1.61)$ & 0.550 \\
\hline \multirow[t]{2}{*}{ Depression diagnosis } & Unipolar depression & 724 (74.9) & $243(25.1)$ & Reference category & \\
\hline & Bipolar depression & $175(71.4)$ & 70 (28.6) & $1.11(0.73-1.67)$ & 0.633 \\
\hline \multirow[t]{2}{*}{ Psychotic features } & Yes & $131(76.2)$ & $41(23.8)$ & $1.05(0.68-1.63)$ & 0.827 \\
\hline & No & $768(73.8)$ & $272(26.2)$ & Reference category & \\
\hline \multirow[t]{2}{*}{ Personality disorder } & Yes & $118(69.8)$ & $51(30.2)$ & $0.88(0.57-1.34)$ & 0.548 \\
\hline & No & $781(74.9)$ & $262(25.1)$ & Reference category & \\
\hline & $20-35$ & $474(75.0)$ & $158(25.0)$ & $1.09(0.62-1.94)$ & 0.761 \\
\hline & $\geq 36$ & $356(72.8)$ & $133(27.2)$ & $1.15(0.64-2.07)$ & 0.642 \\
\hline \multirow[t]{2}{*}{ MADRS-S score after ECT } & $0-10$ & $375(77.6)$ & $108(22.4)$ & Reference category & \\
\hline & $\geq 11$ & $524(71.9)$ & $205(28.1)$ & $1.49(1.09-2.05)$ & 0.013 \\
\hline \multirow[t]{3}{*}{ Memory score before ECT $\dagger$} & 0 & $370(60.6)$ & $241(39.4)$ & Reference category & \\
\hline & $1-2$ & $336(83.0)$ & $69(17.0)$ & $0.25(0.18-0.35)$ & $<0.001$ \\
\hline & $3-4$ & $193(98.5)$ & $3(1.5)$ & $0.02(0.01-0.05)$ & $<0.001$ \\
\hline \multirow[t]{3}{*}{ No. of ECT sessions } & $1-5$ & $109(69.0)$ & $49(31.0)$ & Reference category & \\
\hline & $6-9$ & $539(76.2)$ & $168(23.8)$ & $0.67(0.43-1.02)$ & 0.062 \\
\hline & $\geq 10$ & $251(72.3)$ & $96(27.7)$ & $0.89(0.56-1.43)$ & 0.636 \\
\hline \multirow[t]{3}{*}{ Electrode placement } & Unilateral & $823(74.1)$ & $287(25.9)$ & Reference category & \\
\hline & Bitemporal & $49(75.4)$ & $16(24.6)$ & $1.53(0.78-3.00)$ & 0.221 \\
\hline & Bifrontal & $27(73.0)$ & $10(27.0)$ & $1.33(0.58-3.09)$ & 0.500 \\
\hline \multirow[t]{2}{*}{ Lithium } & Yes & $133(69.3)$ & $59(30.7)$ & $1.58(1.04-2.41)$ & 0.033 \\
\hline & No & $766(75.1)$ & $254(24.9)$ & Reference category & \\
\hline \multirow[t]{2}{*}{ Lamotrigine } & Yes & $99(76.2)$ & $31(23.8)$ & $0.71(0.43-1.19)$ & 0.196 \\
\hline & No & $800(73.9)$ & $282(26.1)$ & Reference category & \\
\hline \multirow[t]{2}{*}{ Valproate } & Yes & $25(71.4)$ & $10(28.6)$ & $0.87(0.38-2.02)$ & 0.751 \\
\hline & No & $874(74.3)$ & $303(25.7)$ & Reference category & \\
\hline \multirow[t]{2}{*}{ Benzodiazepines } & Yes & $390(73.4)$ & $141(26.6)$ & $1.00(0.74-1.35)$ & 0.995 \\
\hline & No & $509(74.7)$ & $172(25.3)$ & Reference category & \\
\hline \multirow[t]{2}{*}{ Other antiepileptic medication } & Yes & $67(73.6)$ & $24(26.4)$ & $0.96(0.55-1.66)$ & 0.879 \\
\hline & No & $832(74.2)$ & $289(25.8)$ & Reference category & \\
\hline \multirow[t]{2}{*}{ Antipsychotic medication } & Yes & $370(73.6)$ & $133(26.4)$ & $0.93(0.68-1.26)$ & 0.641 \\
\hline & No & $529(74.6)$ & $180(25.4)$ & Reference category & \\
\hline
\end{tabular}

Adjusted model calculated by logistic regression. Least square optimization used to calculate CIs and $P$ values.

*Adjusted for all variables in the table.

$\uparrow$ Subjective score on the memory item of the comprehensive psychopathological rating scale: $0=$ memory as usual, $2=$ occasional increased lapses of memory, 4 = reports of socially inconvenient or disturbing loss of memory. 
TABLE 3. Associations Between SMW and Factors of Interest Among Patients With Unilateral Electrode Placement

\begin{tabular}{|c|c|c|c|c|c|}
\hline & & \multirow{2}{*}{$\frac{\text { No SMW }}{n(\%)}$} & \multirow{2}{*}{$\begin{array}{l}\text { SMW } \\
\text { n (\%) }\end{array}$} & \multicolumn{2}{|c|}{ Adjusted Model* } \\
\hline & & & & OR $(95 \%$ CI) & $\boldsymbol{P}$ \\
\hline \multirow[t]{2}{*}{ Sex } & Female & $455(68.6)$ & $208(31.4)$ & Reference category & \\
\hline & Male & $368(82.3)$ & $79(17.7)$ & $0.35(0.26-0.49)$ & $<0.001$ \\
\hline \multirow[t]{3}{*}{ Age, y } & $18-39$ & $176(69.0)$ & $79(31.0)$ & $1.69(1.07-2.66)$ & 0.024 \\
\hline & $40-64$ & $405(75.0)$ & $135(25.0)$ & $1.11(0.76-1.60)$ & 0.598 \\
\hline & $\geq 65$ & $242(76.8)$ & $73(23.2)$ & Reference category & \\
\hline \multirow[t]{2}{*}{ Depression diagnosis } & Unipolar depression & $661(74.7)$ & $224(25.3)$ & Reference category & \\
\hline & Bipolar depression & $162(72.0)$ & $63(28.0)$ & $1.08(0.74-1.57)$ & 0.685 \\
\hline \multirow[t]{2}{*}{ Psychotic features } & Yes & $109(74.7)$ & $37(25.3)$ & $1.18(0.74-1.86)$ & 0.484 \\
\hline & No & $714(74.1)$ & $250(25.9)$ & Reference category & \\
\hline \multirow[t]{2}{*}{ Personality disorder } & Yes & $110(71.0)$ & $45(29.0)$ & $0.83(0.54-1.29)$ & 0.414 \\
\hline & No & $713(74.7)$ & $242(25.3)$ & Reference category & \\
\hline \multirow[t]{3}{*}{ MADRS-S score before ECT } & $0-19$ & $64(75.3)$ & $21(24.7)$ & Reference category & \\
\hline & $20-35$ & $434(75.3)$ & $142(24.7)$ & $1.02(0.56-1.84)$ & 0.953 \\
\hline & $\geq 36$ & $325(72.4)$ & $124(27.6)$ & $1.16(0.63-2.13)$ & 0.632 \\
\hline \multirow[t]{2}{*}{ MADRS-S score after ECT } & $0-10$ & $341(77.5)$ & $99(22.5)$ & Reference category & \\
\hline & $\geq 11$ & $482(71.9)$ & $188(28.1)$ & $1.52(1.09-2.11)$ & 0.013 \\
\hline \multirow[t]{3}{*}{ Memory score before ECT $\dagger$} & 0 & $354(61.5)$ & $222(38.5)$ & Reference category & \\
\hline & $1-2$ & $305(83.1)$ & $62(16.9)$ & $0.27(0.19-0.37)$ & $<0.001$ \\
\hline & $3-4$ & $164(98.2)$ & $3(1.8)$ & $0.02(0.01-0.07)$ & $<0.001$ \\
\hline \multirow[t]{3}{*}{ No. of ECT sessions } & $1-5$ & $99(68.3)$ & $46(31.7)$ & Reference category & \\
\hline & $6-9$ & $485(76.3)$ & $151(23.7)$ & $0.61(0.39-0.95)$ & 0.030 \\
\hline & $\geq 10$ & $239(72.6)$ & $90(27.4)$ & $0.88(0.55-1.43)$ & 0.617 \\
\hline \multirow[t]{2}{*}{ Pulse width, ms } & $0.25-0.47$ & $180(76.9)$ & $54(23.1)$ & Reference category & \\
\hline & $0.50-1.00$ & $643(73.4)$ & $233(26.6)$ & $1.61(1.05-2.47)$ & 0.028 \\
\hline \multirow[t]{2}{*}{ Freqency, Hz } & $20-65$ & $457(73.8)$ & $162(26.2)$ & Reference category & \\
\hline & $70-120$ & $366(74.5)$ & $125(25.5)$ & $0.98(0.69-1.38)$ & 0.909 \\
\hline \multirow[t]{2}{*}{ Duration, s } & $2.0-7.4$ & $392(75.4)$ & $128(24.6)$ & Reference category & \\
\hline & $7.5-8.0$ & $431(73.1)$ & 159 (26.9) & $1.35(0.98-1.85)$ & 0.068 \\
\hline \multirow[t]{2}{*}{ Electric current, $\mathrm{mA}$} & $600-800$ & $437(75.5)$ & $142(24.5)$ & Reference category & \\
\hline & $850-930$ & $386(72.7)$ & $145(27.3)$ & $1.21(0.85-1.71)$ & 0.283 \\
\hline
\end{tabular}

Adjusted model calculated by logistic regression. Least square optimization used to calculate CIs and $P$ values.

All electrical settings correspond to information from first treatment in series.

*Adjusted for all variables listed in the table.

$\dagger$ Subjective score on the memory item of the comprehensive psychopathological rating scale: $0=$ memory as usual, $2=$ occasional increased lapses of memory, 4 = reports of socially inconvenient or disturbing loss of memory.

performance is that ECT has a stronger antidepressive effect for older patients than for younger patients ${ }^{30}$ and that patients are likely to report less deterioration of their memory if other depressive symptoms are improved.

Formula-based stimulus dosing is standard in Sweden, and dose titration according to seizure threshold is uncommon. If electrical doses are not adequately adjusted to age and sex, this could contribute to the increased risk of SMW among women and younger patients. ${ }^{31,32}$ The optimal dosing strategy is yet to be determined.

Patients with worse subjective memory at baseline were significantly less likely to experience SMW. This can be reassuring for patients who experience subjective memory disturbances before ECT.

High electrical charges have been associated with greater anterograde memory disturbances than low electrical charges. ${ }^{21} \mathrm{We}$ found that longer pulse widths were associated with greater risk of SMW. It needs to be established if adjusting this factor can affect the risk of SMW. When weighing the relative benefits and risks of different stimulus settings, both the symptom-reducing effects and the adverse effects need to be considered. Setting the electrical doses to low is associated with reduced symptom-relieving effect. ${ }^{21}$ A sufficient symptom-reducing effect should most often be prioritized.

This study showed no evidence of differences in the risk of SMW between patients treated with unilateral and bifrontal or bitemporal ECT. In line with this finding, recent studies do not indicate clinically relevant differences in the cognitive effects of different electrode placements in adequate doses. ${ }^{33}$ Thus, clinicians should not refrain from using bilateral electrode placement out of fear of causing memory disturbances.

In this study, there was a nonsignificant tendency toward a lower risk of SMW among patients receiving 6 to 9 sessions as compared with 5 sessions or fewer. This result needs to be interpreted with caution because of the observational design of the study and the risk of selection bias. The treatment is more 
likely to be terminated early for patients who experience SMW than for patients who do not experience SMW. For patients with long treatment series, the effects of the first treatments on subjective memory may have decreased by the end of the treatment series.

Lithium use was associated with increased risk of SMW. This could possibly be explained by the fact that lithium treatment may lower seizure threshold, ${ }^{32}$ and there are reports of prolonged seizures. ${ }^{34}$ However, the effect of lithium on SMW was modest. Lithium doses in Sweden are most often adjusted to a serum concentration of 0.5 to $0.8 \mathrm{mmol} / \mathrm{L}$. During ECT, it is common practice to further reduce the dose and/or withhold the dose the night before ECT.

A strength of this study is the large sample size including more than 1000 subjects. The limitations of this study include that no objective cognitive testing was performed; therefore, we cannot compare the subjective reports with the objective test results. Moreover, the reports of SMW were collected within the first week after ECT; thus, the results of this study are not informative of the longer-term outcomes of ECT.

In conclusion, this study shows that subjective memory ratings before and within 1 week after ECT are similar for most patients. Compared with other patient groups, young women are more likely to experience SMW immediately after ECT. For patients treated with unilateral electrode placement who experience SMW, ultrabrief pulse width stimulus could be considered because ultrabrief pulse width seems to be associated with reduced risk of SMW. Remission from depression was also associated with reduced risk of SMW, so an ineffective or too short a treatment series might therefore increase the risk of SMW. Each patient should be monitored with regard to symptoms as well as adverse effects, and the treatment should be adjusted on an individual basis to maximize clinical effect and with efforts to minimize cognitive adverse effects.

\section{REFERENCES}

1. Fink M, Taylor MA. Electroconvulsive therapy: evidence and challenges. JAMA. 2007;298:330-332.

2. Sackeim HA, Prudic J, Fuller R, et al. The cognitive effects of electroconvulsive therapy in community settings. Neuropsychopharmacology. 2007;32:244-254.

3. Lisanby SH, Maddox JH, Prudic J, et al. The effects of electroconvulsive therapy on memory of autobiographical and public events. Arch Gen Psychiatry. 2000;57:581-590.

4. The American Psychiatric Asssociation's Task Force on Electroconvulsive Therapy. The Practice of Electroconvulsive Therapy-Recommendations for Treatment, Training, and Privileging. 2nd ed. Washington, DC: American Psychiatric Publishing; 2001.

5. Semkovska M, McLoughlin DM. Objective cognitive performance associated with electroconvulsive therapy for depression: a systematic review and meta-analysis. Biol Psychiatry. 2010;68: 568-577.

6. Ottosson JO, Odeberg H. Evidence-based electroconvulsive therapy. Acta Psychiatr Scand. 2012;125:177-184.

7. Sackeim HA, Prudic J, Devanand DP, et al. Effects of stimulus intensity and electrode placement on the efficacy and cognitive effects of electroconvulsive therapy. $N$ Engl J Med. 1993;328:839-846.

8. Prudic J, Peyser S, Sackeim HA. Subjective memory complaints: a review of patient self-assessment of memory after electroconvulsive therapy. J ECT. 2000;16:121-132.

9. Rose D, Fleischmann P, Wykes T, et al. Patients' perspectives on electroconvulsive therapy: systematic review. BMJ. 2003; $326: 1363$.
10. Bergsholm P. Patients' perspectives on electroconvulsive therapy: a reevaluation of the review by Rose et al on memory loss after electroconvulsive therapy. $J$ ECT. 2012;28:27-30.

11. Fraser LM, O'Carroll RE, Ebmeier KP. The effect of electroconvulsive therapy on autobiographical memory: a systematic review. $J E C T$. 2008;24:10-17.

12. Berman RM, Prudic J, Brakemeier EL, et al. Subjective evaluation of the therapeutic and cognitive effects of electroconvulsive therapy. Brain Stimul. 2008;1:16-26.

13. Brakemeier EL, Berman R, Prudic J, et al. Self-evaluation of the cognitive effects of electroconvulsive therapy. J ECT. 2011;27:59-66.

14. Coleman EA, Sackeim HA, Prudic J, et al. Subjective memory complaints prior to and following electroconvulsive therapy. Biol Psychiatry. 1996;39: 346-356.

15. Hulur G, Hertzog C, Pearman A, et al. Longitudinal associations of subjective memory with memory performance and depressive symptoms: between-person and within-person perspectives. Psychol Aging. 2014;29: 814-827.

16. Woo YS, Rosenblat JD, Kakar R, et al. Cognitive deficits as a mediator of poor occupational function in remitted major depressive disorder patients. Clin Psychopharmacol Neurosci. 2016;14: $1-16$.

17. Douglas KM, Porter RJ. Longitudinal assessment of neuropsychological function in major depression. Aust $N Z J$ Psychiatry. 2009;43:1105-1117.

18. Sackeim HA. Autobiographical memory and electroconvulsive therapy: do not throw out the baby. J ECT. 2014;30:177-186.

19. Bergsholm P, Schweder LJ. Thoughts about the baby and the bathwater. JECT. 2015;31:73.

20. Semkovska M, McLoughlin DM. Retrograde autobiographical amnesia after electroconvulsive therapy: on the difficulty of finding the baby and clearing murky bathwater. JECT. 2014;30:187-188, discussion 189-190.

21. UK ECT Review Group. Efficacy and safety of electroconvulsive therapy in depressive disorders: a systematic review and meta-analysis. Lancet. 2003;361:799-808.

22. Nordanskog P, Hulten M, Landen M, et al. Electroconvulsive therapy in Sweden 2013: data from the National Quality Register for ECT. JECT. 2015;31:263-267.

23. Ludvigsson JF, Andersson E, Ekbom A, et al. External review and validation of the Swedish national inpatient register. BMC Public Health. 2011;11:450.

24. Socialstyrelsen. Internationell Statistisk Klassifikation av Sjukdomar och Relaterade Hälsoproblem -Systematisk Förteckning, Svensk Version 2011 (ICD-10-SE). Stockholm, Sweden: Socialstyrelsen; 2010.

25. Asberg M, Montgomery SA, Perris C, et al. A comprehensive psychopathological rating scale. Acta Psychiatr Scand Suppl. 1978;5-27.

26. Montgomery S, Asberg M, Jörnestedt L, et al. Reliability of the CPRS between the disciplines of psychiatry, general practice, nursing and psychology in depressed patients. Acta Psychiatr Scand Suppl. 1978;29-32.

27. Svanborg P, Asberg M. A comparison between the Beck Depression Inventory (BDI) and the self-rating version of the Montgomery Asberg Depression Rating Scale (MADRS). J Affect Disord. 2001; 64:203-216

28. Hawley CJ, Gale TM, Sivakumaran T, et al. Defining remission by cut off score on the MADRS: selecting the optimal value. J Affect Disord. 2002;72:177-184.

29. Sinclair JE, Fernie G, Bennett DM, et al. Assessing the association between electrical stimulation dose, subsequent cognitive function and depression severity in patients receiving bilateral 
electroconvulsive therapy for major depressive disorder. J ECT. 2016;32: $159-163$.

30. Nordenskjöld A, von Knorring L, Engström I. Predictors of the short-term responder rate of electroconvulsive therapy in depressive disorders - a population based study. BMC Psychiatry. 2012;12:115.

31. Boylan LS, Haskett RF, Mulsant BH, et al. Determinants of seizure threshold in ECT: benzodiazepine use, anesthetic dosage, and other factors. J ECT. 2000;16:3-18.
32. Galvez V, Hadzi-Pavlovic D, Smith D, et al. Predictors of seizure threshold in right unilateral ultrabrief electroconvulsive therapy: role of concomitant medications and anaesthesia used. Brain Stimul. 2015;8:486-492.

33. Fink M, Petrides G, Kellner C, et al. Change in seizure threshold during electroconvulsive therapy. J ECT. 2008;24:114-116.

34. Sartorius A, Wolf J, Henn FA. Lithium and ECT - concurrent use still demands attention: three case reports. World J Biol Psychiatry. 2005;6:121-124. 